\title{
An Analysis of Online Syllabi for Credit-bearing Library Skills Courses
}

\section{Paul L. Hrycaj}

\begin{abstract}
In an effort to develop some sense of the current state of credit-bearing library skills courses at academic libraries, an analysis was conducted of 100 online syllabi for introductory library skills courses at various colleges and universities. These online syllabi were analyzed for subject content and assessment techniques/teaching methods. The "Information Literacy Competency Standards for Higher Education," created by the Association of College and Research Libraries, were utilized as a framework for categorizing and placing into context the subject content of the syllabi analyzed.
\end{abstract}

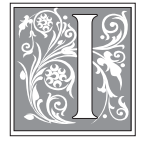

n 2000, the Association of College and Research Libraries created, approved, and published "Information Literacy Competency Standards for Higher Education." One question to consider, some five years after these standards have been published, is: to what extent are these standards being followed by colleges and universities in their library instruction activities? The current study will attempt to gather some information for answering this question. This study is an analysis of 100 online syllabi for credit-bearing college and university library skills courses. These syllabi were analyzed primarily for their subject content, but some other issues were considered as well, such as assessment techniques and teaching methods. (In addition, an appendix lists the required textbooks noted in the syllabi.) It is the author's hypothesis that, because library skills courses are primarily taught by librarians, and (in the author's view) issues of information access are the specialty of librarians, matters of information access are the dominant subject matter of creditbearing college and university library skills courses. This study should provide some evidence to support or undermine this hypothesis.

The results of this study should be an aid to librarians who are beginning to teach library skills classes and are looking for some ideas for developing their own syllabi. Also, these results should be of interest to instructors who have previously taught library skills classes, either to affirm their own instructional approaches or to provide some ideas for different approaches. Finally, the author hopes that this discussion will stimulate some thought as to what topics and material should be covered in library skills courses. If some readers believe that the results of this study indicate approaches to library skills instruction that are askew or misguided, perhaps these readers would be motivated to provide ideas and arguments for alternative approaches.

Paul L. Hrycaj is Reference $\mathcal{E}$ Instruction Librarian at Louisiana State University Libraries; e-mail: phryca1@lsu.edu. 


\section{Literature Review}

The document published by the Association of College and Research Libraries titled "Information Literacy Competency Standards for Higher Education" (hereafter, "Standards") represents an important attempt to define and clarify the skills that make up the overall ability to be an effective user of information-something that every well-educated person should be. ${ }^{1}$ As such, these standards can be used in various ways, but particularly as a guide for curricula and as a way to assess education and instruction programs.

The Standards are phrased in terms of what the "information literate student" is able to do. To paraphrase: Standard One says that the information literate student is able to determine his or her information need; Two, that he or she can access information efficiently and effectively; Three, that he or she can evaluate information and incorporate it into his or her knowledge base; Four, that he or she can use information effectively for a particular purpose; and Five, that the information literate student understands the ethical, legal, and sociological issues surrounding the use of information.

The ACRL also expands on each standard by describing "performance indicators" and "outcomes." For instance, Standard One has four performance indicators. The second performance indicator for Standard One, for example, says that, "the information literate student identifies a variety of types and formats of potential sources for information." This performance indicator has six stated outcomes; for example, the fourth one of these says, "Identifies the purpose and audience of potential resources (e.g., popular vs. scholarly, current vs. historical)." Performance indicators are designated by numbers, and outcomes by small letters. For example, the previously noted standard and its associated performance indicator and outcome can be identified as "1.2.d": i.e. Standard One, Performance Indicator 2, Outcome d. This type of identification will be employed later in this study.
There do not appear to be any other analyses of syllabi of information skills courses published in the literature. One study that, like the current one, attempts to arrive at some sense of the state of credit-bearing library skills courses in academic libraries is Barbara Wittkopf's "A Look at the State of BI Credit Courses in ARL-Member Libraries," in which Wittkopf surveyed Association of Research Libraries (ARL) members on the particulars of their bibliographic information (BI) credit courses. ${ }^{2}$ Doing a survey of the content of BI credit courses is in many ways preferable to learning about these courses through analyzing their syllabi, for syllabi tend to be condensed and vague and may not answer the specific questions about the course in which the researcher is interested. A survey represents an opportunity to get answers to exactly the questions in which one is interested. Unfortunately, surveys take a great deal of time to design, distribute, gather, and analyze. Wittkopf's study, while innovative, was done over a decade ago, and the report of its results is very brief. It does not, for instance, go into detail about the subjects covered in the credit courses it reviewed, as the current study does.

One study that recognized the utility of the ACRL Standards as a device for assessing information literacy activities is Davidson, McMillen, and Maughan's "Using the ACRL Information Literacy Competency Standards for Higher Education to Assess a University Library Instruction Program." ${ }^{3}$ In considering how to assess the instruction program of the Reference and Instruction Department at Oregon State University, the authors of this study note how they decided to use the ACRL Standards:

One means of assessing a program is to select benchmarks for comparison. One looks at the "gap" between existing practice and desired position, and analyzes what needs to be done to close that gap. Certainly standards for library instruction 
programs in academic institutions have existed for years. The ACRL ILC's [Information Literacy Competency Standards for Higher Education] seemed the logical benchmark, however, because it provides the most current model and has been adopted by several states' Boards of Higher Education. ${ }^{4}$

As this passage indicates, this assessment effort at Oregon State University used the ACRL Standards as a benchmark to indicate what an information literacy program should be doing. But the current study, on the contrary, will use the ACRL Standards simply as a framework to help to determine what many library instruction programs are doing. Once this has been determined, it will be a further question whether these instruction programs are headed in the right direction or not.

As indicated earlier, it is the author's view that issues of information access (e.g., subject headings, classification systems, bibliographic databases) are the strongest areas of specialization for librarians. One paper that seems to agree with this point and recommends it as a prescription for guiding library instruction programs is Feinberg and King's "Short-Term Library Skill Competencies: Arguing for the Achievable." ${ }^{5}$ In this paper, Feinberg and King acknowledge the trend in the library instruction literature of advocating the teaching of critical thinking and higher order conceptual skills in library instruction, and they suggest that this approach is misguided: "What these writers exhort us to do, e.g., teach logic, abstract reasoning, the organization of literature in different disciplines, and critical evaluation of sources, are the things we seem to do least well. And those things we do best, such as teaching students library mechanics, helping them to achieve short-term competencies, and developing confidence in using the library, are what the leaders disparage as having limited value."
One aspect of the present study is that it is an attempt, through an analysis of syllabi, to see which approach the current practice of library instruction favors, what we might call the "short-term library competencies approach" as opposed to the "critical thinking approach."

\section{Methodology}

The author searched for and gathered 100 online syllabi for library skills courses in the months of January, February, and March of 2005. These syllabi had to be for credit-bearing introductory library skills courses at a college or a university, and each one had to be specific enough to lay out the main topics and assessment methods of the course. Also, for the sake of consistency in the study, syllabi for introductory library skills courses that had a subject focus (e.g., courses that concentrated on humanities or social sciences research) were rejected. In a number of cases, the dates of the syllabi analyzed were not specified, so the syllabi for this study cannot be assumed to be for the 2004-2005 school year. While the number of 100 is somewhat arbitrary as a target figure for the syllabi sample, the author had some difficulty in finding enough syllabi to meet this number. This suggests that, at the time of gathering the data for this study, it is unlikely that there were many more syllabi that met the author's criteria for usability for this study.

The author used the search engine Google and a number of different search phrases to find the syllabi of interest, viz.: "information literacy" syllabus; "library research" syllabus; "research skills" library syllabus; "library resources" syllabus; "academic research" syllabus; "information research" syllabus; "library skills" syllabus; "information competency" syllabus; "information resources" syllabus; and "basic research" syllabus. Using these different phrases often retrieved similar results, again supporting the notion that it is unlikely that a significant number of syllabi meeting the criteria for this study were missed. 
It should be noted that, because Google was the sole means used to retrieve the syllabi analyzed in this study, any online syllabi that were accessible only via an institution's course management software or some other password protection mechanism at the time of this study were necessarily excluded from the author's sample. In all likelihood, the syllabi that fall into this category are quite numerous, so this feature of the author's methodology clearly reduced the sample size for this study.

In general, a topic was counted as being covered by a syllabus in this study only if it was specifically mentioned as a topic

\begin{tabular}{|c|c|c|c|c|}
\hline \multicolumn{5}{|c|}{$\begin{array}{c}\text { TABLE } 1 \\
\text { Topics Covered in Online Syllabi }\end{array}$} \\
\hline Topics & $\%$ & Rank & $\begin{array}{c}\text { ACRL } \\
\text { Standard }\end{array}$ & $\begin{array}{l}\text { Performance } \\
\text { Indicator/ } \\
\text { Outcome }\end{array}$ \\
\hline Periodical databases & 94 & 1 & 2 & $3 \mathrm{c}$ \\
\hline Web searching & 93 & 2 & 2 & $3 c$ \\
\hline Online catalog & 92 & 3 & 2 & $3 c$ \\
\hline Web site evaluation & 79 & 4 & 3 & $2 a, c$ \\
\hline Writing citations & 76 & 5 & 5 & $3 a$ \\
\hline Monograph evaluation & 75 & 6 & 3 & $2 \mathrm{a}$ \\
\hline Research strategy & 75 & 7 & 2 & $3 a, b$ \\
\hline Periodical evaluation & 74 & 8 & 3 & $2 \mathrm{a}$ \\
\hline Reference sources & 66 & 9 & 1 & $1 \mathrm{c}, 2 \mathrm{c}$ \\
\hline Classification systems & 57 & 10 & 2 & $3 b$ \\
\hline Research topics & 54 & 11 & 1 & $1 b$ \\
\hline Library of Congress subject headings & 47 & 12 & 2 & $2 d$ \\
\hline Plagiarism & 40 & 13 & 5 & $2 f$ \\
\hline Popular vs. Scholarly sources & 39 & 14 & 1 & $2 \mathrm{~d}$ \\
\hline Government documents & 38 & 15 & 1 & $2 \mathrm{c}$ \\
\hline Library tours & 32 & 16 & 2 & $3 b$ \\
\hline Copyright & 32 & 17 & 5 & $1 d$ \\
\hline Boolean searching & 25 & 18 & 2 & $2 d$ \\
\hline Periodical literature & 21 & 19 & 1 & $2 \mathrm{a}, 2 \mathrm{c}$ \\
\hline Statistics & 19 & 20 & 1 & $2 \mathrm{c}, 2 \mathrm{f}$ \\
\hline Print indexes & 18 & 21 & 2 & $3 a$ \\
\hline Censorship & 11 & 22 & 5 & $1 \mathrm{c}$ \\
\hline Concept of information & 10 & 23 & 1 & $2 \mathrm{a}$ \\
\hline Writing a research paper & 8 & 24 & 4 & $1 a-d, 3 a-d$ \\
\hline Interlibrary loan & 8 & 25 & 2 & $3 \mathrm{c}$ \\
\hline Biographical information & 7 & 26 & 1 & $2 \mathrm{c}$ \\
\hline Book reviews & 7 & 27 & 1 & $2 \mathrm{c}$ \\
\hline How information is produced & 6 & 28 & 1 & $2 \mathrm{a}$ \\
\hline
\end{tabular}


in the syllabus. For instance, although Library of Congress Subject Headings often are discussed in the context of a discussion of a library's online catalog, the topic of Library of Congress Subject Headings was not counted as being covered by a syllabus just because the topic of the online catalog was specifically referred to in the syllabus. Also, just because a syllabus included a plagiarism policy for the students' work in the course, this in itself did not lead to counting the topic of plagiarism for this syllabus; again, the topic of plagiarism would have to be listed explicitly as one of the course topics in order to be counted. Textbooks noted in the Appendix had to be required textbooks; books that were simply recommended or suggested reading for the course were not listed.

The raw results for the topics covered in the online syllabi examined are reported in table 1 . The results are displayed in descending order of occurrences, and the number of the particular ACRL Standard associated with each topic is indicated as well. For the sake of simplicity, ties in number of occurrences for different topics were arbitrarily assigned a consecutive rank. Topics covered by fewer than five syllabi were not displayed. The particular ACRL Performance Indicator and Outcome associated with each topic are also indicated in a separate column. The author then added up each "occur-

\begin{tabular}{|l|c|c|}
\hline \multicolumn{3}{|c|}{$\begin{array}{c}\text { TABLE 3 } \\
\text { Occurrences of Assessment } \\
\text { Techniques and Teaching Methods }\end{array}$} \\
\hline \hline $\begin{array}{l}\text { Assessment technique/ } \\
\text { teaching method }\end{array}$ & $\%$ & Rank \\
\hline Final projects & 67 & 1 \\
\hline Midterms & 45 & 2 \\
\hline Final exam & 42 & 3 \\
\hline Annotated bibliography & 31 & 4 \\
\hline In-class projects & 17 & 5 \\
\hline In-class presentations & 12 & 6 \\
\hline Online tutorials & 9 & 7 \\
\hline
\end{tabular}

\begin{tabular}{|c|c|c|}
\hline \multicolumn{3}{|c|}{ TABLE 2 } \\
Accumulated Occurrences of Each \\
ACRL Standard \\
\hline \hline $\begin{array}{c}\text { ACRL } \\
\text { Standard }\end{array}$ & $\begin{array}{c}\text { \# of } \\
\text { occurrences }\end{array}$ & Rank \\
\hline 1 & 267 & 2 \\
\hline 2 & 541 & 1 \\
\hline 3 & 228 & 3 \\
\hline 4 & 8 & 5 \\
\hline 5 & 159 & 4 \\
\hline
\end{tabular}

rence" of a particular ACRL Standard, an "occurrence" of a Standard being the occurrence of a topic in a syllabus that is associated with that Standard. So, for example, Syllabus A referring to a discussion of periodical databases and research strategy, and Syllabus B referring to a discussion of the online catalog and Web searching, all together would count as four occurrences in these syllabi of ACRL Standard Two.

The accumulated number of occurrences of a particular Standard in a group of syllabi is the addition of all of the topics covered in the syllabi that are associated with that Standard. So, for instance, the accumulated number of occurrences of Standard Two in the syllabi is the addition of all of the times "periodical databases," "Web searching," "online catalog," "research strategy," etc., are referred to in the group of syllabi. The accumulated occurrences of each ACRL Standard in the syllabi reviewed in this study are reported in table 2. It is the author's view that the accumulated occurrences of the ACRL Standards provide evidence of the intensity of interest or concern with a particular Standard: the higher the number of occurrences of a particular Standard in a group of syllabi, the greater the interest or concern with that Standard in that group of syllabi.

Finally, a count of occurrences of some assessment techniques and teaching methods referred to in the syllabi is given in table 3. 


\section{Results}

As table 2 indicates, Standard Two has by far the greatest number of occurrences in the online syllabi compared to the other standards, supporting the author's hypothesis that matters of information access are the dominant subject matter of credit-bearing college and university library skills courses.

Standard One placed a distant second to Standard Two. Most of the topics referred to in the syllabi related to Standard One have to do with types of information sources, which is the focus of Performance Indicator Two ("The information literate student identifies a variety of types and formats of potential sources for information"). The most popular of these was the topic of "Reference Sources." But another popular Standard One topic was "Research topics," which is in the area of Performance Indicator One ("The information literate student defines and articulates the need for information"). Certainly, librarians are experts on types of information sources, and they are also experienced in defining research topics, since defining an information need is one way of describing a librarian's activity in the reference interview, the kind of thing librarians do constantly in their reference desk work. Hence, it is unsurprising that subjects pertaining to ACRL Standard One should be covered frequently in library skills courses.

That the number of occurrences of subjects pertaining to Standard Three came in a close third in this study is perhaps a bit surprising. For, as noted above, Feinberg and King claim that "teaching logic," "abstract reasoning," and "critical evaluation of sources," all Standard Three topics, are some of the things library instructors "do least well." It is certainly the author's view that analyzing arguments, synthesizing information, and drawing conclusions based on one's understanding of various sources of information-all Standard Three skills-are best done in the context of discipline-based courses. For it is difficult for students to exercise these skills without completely reading and digesting material presented in periodical articles, monographs, and Web sites, and this would be done more appropriately in the context of a discipline course than in a non-subject-related, general library skills course.

Notice, however, that in table 1 all of the Standard Three occurrences in the syllabi have to do with the evaluation of information sources. The evaluation of information sources can be confined solely to Standard Three, Performance Indicator Two ("The information literate student articulates and applies initial criteria for evaluating both the information and its sources"). Such evaluation of sources can focus on evaluative criteria such as currency, authority, documentation of sources, and bias, which can be determined without necessarily delving into the actual content of the sources. At the very least, the performance indicators for Standard Three other than Performance Indicator Two deal more with digesting and synthesizing information, and the subjects of the syllabi reviewed in this study did not cover these matters in any direct way. (Indeed, it seems that Standard Three could have been split into two standards, one focusing on evaluation, the other on incorporating information into one's knowledge base; these two very different concepts are simply conjoined in Standard Three.) So it can be argued that the exercise of Standard Three in the syllabi reviewed in this study doesn't indicate significant content analysis in these syllabi. Nevertheless, the prevalence of resource evaluation in the syllabi indicates that instructors of introductory library skills courses are concerned about more than just information access and types of information sources. This may be due, at least in part, to the focus on matters of critical thinking, abstract reasoning, etc., in the literature on information literacy. ${ }^{7}$

Standard Five ranked in fourth place, indicating that, as a group, the ethical, legal, and social issues surrounding information use are not a high priority in 
introductory library skills courses. The most important aspects of Standard Five in the syllabi reviewed are the writing of citations and the related issue of plagiarism, and the topic of writing citations actually ranks very highly on the list of syllabi topics (fifth). This point appears to indicate the concern library instructors have with the ethical use of information by their students.

The lowest ranking ACRL Standard was Standard Four. This suggests that issues related to putting a finished "information product" together are not a priority for library instructors. Certainly instruction on such matters as communicating clearly in an information product are probably best left to writing and discipline instructors, who are in a better position to assign full-blown writing and other information-presentation projects than instructors of library skills courses.

A concern with information products in the syllabi is supported to some degree by the "Assessment technique/teaching method" part of this study, reported in table 3. For example, 67 percent of syllabi indicated a final project requirement in their courses. This suggests that library instructors are concerned that their students be able to assemble finished information products, though this could also be because a final project can be a good opportunity for students to exercise many of the ACRL Standards, Performance Indicators, and Outcomes. For instance, a popular type of final project noted in the reviewed syllabi was the annotated bibliography, which was assigned in 31 percent of the syllabi. Such an assignment can require students to develop a topic (Standard One), be familiar with particular types of information sources, such as reference works (Standard One), access various types of information (Standard Two), evaluate the sources retrieved in the search process (Standard Three), and assemble a selected group of sources and brief evaluative notes about them in a finished product (Standard Four) using proper citation formats (Standard Five).
Annotated bibliographies also have the advantage of involving information source evaluation while staying clear of requiring students to delve deeply into discipline-related material.

It should be noted here that the most popular type of assessment used in the syllabi was not actually mentioned in table 3, viz. regular homework assignments given at various times during the class. This type of assessment is so obvious that it was not explicitly listed in the table of assessment types, but virtually 100 percent of the syllabi referred to the use of homework assignments for assessment in their associated courses.

\section{Limitations/Weaknesses of this Study}

There are a number of caveats to this study that need to be brought to the reader's attention. First of all, this study did not (and in most cases could not) take into account the amount of time spent on the topics in each course represented by the syllabi. And since this study draws conclusions regarding emphasis on or concern with the various ACRL Standards, the issue of time spent on topics seems relevant to these conclusions. For instance, suppose that 60 syllabi included the online catalog as a topic and 50 syllabi included source evaluation. If twice as much time was spent covering source evaluation in every course that treated this topic compared with the time spent on the online catalog, it seems at best questionable to conclude that, as a whole, ACRL Standard Two is better represented in these syllabi than ACRL Standard Three. But, again, this study is basing its conclusions regarding emphasis on ACRL Standards solely on topic count, so this methodology would require concluding that Standard Two is better represented than Standard Three in this hypothetical case. Hence, if the topics covered in the various courses under review in this study were given significantly disparate emphasis in these courses, then that could throw into question the results of this study. But because trying to take into account the emphasis a topic is given 
within each course would have made the study much more complex, and in many cases would have been impossible to determine, this factor was not taken into account in this study.

A similar caveat is that this study is limited to what is explicitly mentioned in the syllabi. Because syllabi are typically very concise, they often leave out some details. So, for instance, if many courses represented by the syllabi covered Boolean searching in the course of a discussion of searching the online catalog, but didn't mention Boolean searching explicitly in the syllabus for the course, this would produce skewed results for this study. And, of course, such an omission of details could have happened for many different topics covered in these courses.

It was noted above that, if final projects are taken into account in addition to the course topics, then ACRL Standard Four is better represented in the syllabi than would be indicated by the results of table 1. It might be pointed out that taking similar account of assignments could bolster the representation of Standard Three in the courses under review. For, the point might go, evaluation, critical thinking, and information synthesis are issues that are not usually discussed as topics, but are exercised instead in class assignments. So it could turn out that Standard Three is better represented in the courses corresponding to the syllabi reviewed than our discussion above would indicate. This is a fair point, but we should bear in mind that the syllabi reviewed in this study were not explicit enough about the content of assignments to draw any clear conclusions about which Standards they exercised.

While this study provides some evidence for the current state of library instruction credit courses, unfortunately the sample of online resumes doesn't appear to be large enough to support an unqualified extrapolation of the results to creditbearing library instruction courses generally. Consider a rough estimate of the current number of credit-bearing library instruction courses: according to a 1997 study, credit library instruction courses in 1995 were provided at approximately 30 percent of colleges and universities. ${ }^{8}$ By one recent count, ${ }^{9}$ the number of colleges and universities in the United States for 2002-2003 is 4,168. Assuming that these figures are still roughly correct, the number of colleges and universities offering credit-bearing library instruction courses would be approximately 1,250. Let's assume that each one of these institutions offers an introductory library skills course of the type whose syllabi are the subject of this study, which would give us a target population of 1,250 syllabi. According to one online statistics calculator, ${ }^{10}$ the size of the sample needed to make a 95 percent accurate generalization from the sample to this target population is 406 . Clearly, the number of syllabi reviewed in this study is well below the sample size necessary for generalizing the study's results to all credit library instruction courses. On the other hand, this sample size calculation is based on the notion that nothing is known about the sample. On the contrary, though, we know enough about the sample (i.e., that it was retrieved from a search engine using various search phrases and that the syllabi were from a variety of sizes of colleges and universities) so that there doesn't seem to be any "bias" in the sample. So this study does seem to give some evidence for the state of credit-bearing introductory library skills courses in general, though clearly the size of the sample leaves some room for doubt about how strong this evidence is.

Finally, the syllabi compiled for this study are all for "stand-alone" library skills courses. But there is a considerable literature on library instruction based on collaboration between library instructors and discipline faculty members. ${ }^{11}$ If collaborative library instruction is widespread and differs significantly from stand-alone library skills course instruction, then even an accurate picture of stand-alone library skills courses might not represent the general nature of library 
instruction in higher education today. So one must be cautious if one is inclined to generalize from the results of this study to the overall state of library skills instruction in higher education.

\section{Conclusion}

In summary, this study of online syllabi gives qualified support to the author's hypothesis that matters of information access, which are the focus of ACRL Standard Two, are the dominant subject matter of credit-bearing college and university library skills courses. Evaluation of information sources, part of the focus of ACRL Standard Three, was also well represented in the syllabi reviewed in this study. But the other parts of Standard Three, dealing with critical thinking and information synthesis, did not appear to have much representation in the syllabi, although the vagueness of the syllabi, particularly on the content of class assignments, leaves this claim somewhat open to question. Regular homework assignments were, not surprisingly, almost a universally used assessment technique noted in the syllabi. Somewhat surprisingly, final projects were a very popular assessment technique, and annotated bibliographies were a specific type of project that was commonly assigned.

While there are significant limitations to this study, the online syllabi reviewed provide some insight into the current state of credit-bearing library skills courses in colleges and universities. But surveys dealing with instruction content and teaching methods administered to instructors of stand-alone library skills courses, as well as instructors involved in collaborations with discipline faculty, would be very welcome for throwing even more light on this subject.

\section{Notes}

1. Association of College \& Research Libraries, Information Literacy Competency Standards for Higher Education (Chicago: Association of College \& Research Libraries, 2000). Available online at http://www.ala.org/ala/acrl/acrlstandards/informationliteracycompetency.htm.

2. Barbara J. Wittkopf, "A Look at the State of BI Credit Courses in ARL-Member Libraries," Research Strategies 9 (Fall 1991): 162-63.

3. Jeanne R. Davidson, Paula S. McMillen, and Laurel S. Maughan, "Using the ACRL Information Literacy Competency Standards for Higher Education to Assess a University Library Instruction Program," Journal of Library Administration 36, no. 1/2 (2002): 97-121.

4. Ibid., 99.

5. Richard Feinberg and Christine King, "Short-Term Library Skill Competencies: Arguing for the Achievable," College \& Research Libraries 49 (Jan. 1988): 24-28.

6. Ibid., 25.

7. As noted above, the "critical thinking" approach to bibliographic instruction was well represented in the literature even at the time of Feinberg and King's paper (i.e. 1988); the authors cite this approach in a number of papers at the beginning of their discussion. And, since the time of Feinberg and King's paper, this approach has continued to find many proponents in the library science literature. Some notable examples of this are: Sonia Bodi, "Critical Thinking and Bibliographic Instruction: the Relationship," Journal of Academic Librarianship 14 (July 1988): 150-53; Cerise Oberman, "Avoiding the Cereal Syndrome; or, Critical Thinking in the Electronic Environment," Library Trends 39 (Winter 1991): 189-202; and Craig Gibson, "Critical Thinking: Implications for Instruction," RQ, 35 (Fall 1995), 27-35.

8. Linda Shirato and Joseph Badics, "Library Instruction in the 1990's: A Comparison with Trends in Two Earlier LOEX Surveys," Research Strategies 15, no. 4 (1997): 223-37.

9. "Number of U.S. Colleges and Universities and Degrees Awarded," infoplease, based on 2002-2003 figures from the Chronicle of Higher Education. [Accessed 20 July 2005]. Available online at www.infoplease.com.

10. Creative Research Systems, "Sample Size Calculator," using a standard statistics formula with a confidence level of $95 \%$ and a confidence interval of 4. [Accessed on 20 July 2005]. Available online at www.surveysystem.com/sscalc.htm.

11. Some examples of this literature are: Richard Raspa and Dane Ward, The Collaborative Imperative: Librarians and Faculty Working Together in the Information Universe (Chicago: Associa- 
tion of College and Research Libraries, 2000); David Carlson and Ruth H. Miller, “Librarians and Teaching Faculty: Partners in Bibliographic Instruction," College and Research Libraries 45, no. 6 (1994): 483-91; Barbara F. Schloman and Rodney M. Feldmann, "Developing Information Gathering Skills in Geology Students Through Faculty-Librarian Collaboration," Science E Technology Libraries 14, no. 2 (Winter 1993): 35-47; Linda L. Stein and Jane M. Lamb, "Not Just Another BI: Faculty-Librarian Collaboration to Guide Students Through the Research Process," Research Strategies 16, no. 1 (1998): 29-39; Christine Black, Sarah Crest, and Mary Volland, "Building a Successful Information Literacy Infrastructure on the Foundation of Librarian-Faculty Collaboration," Research Strategies 18, no. 3 (2001): 215-25; Jennifer L. Dorner, Susan E. Taylor, and Kay Hodson-Carlton, "Faculty-Librarian Collaboration for Nursing Information Literacy: A Tiered Approach," Reference Services Review 29, no. 2 (2001): 132-40; Ann M. Fiegen, Bennett Cherry, and Kathleen Watson, "Reflections on Collaboration: Learning Outcomes and Information Literacy Assessment in the Business Curriculum," Reference Services Review 30, no. 4 (2002): 307-18. 


\section{APPENDIX \\ Required Textbooks Noted on Syllabi}

Note: The number of syllabi referring to a textbook is given at the end of the citation for the textbook in square brackets; textbooks are ordered by this number in descending order. Any textbook mentioned by only one syllabus has no bracketed number at the end of its citation.

List, Carla. Information Research. 2nd ed. Dubuque, IA: Kendall/Hunt, 2002 [8].

Bolner, Myrtle S., and Gayle A. Poirier. The Research Process: Books E Beyond. Dubuque, IA: Kendall/Hunt [5].

Quaratiello, Arlene Rodda. The College Student's Research Companion. New York: NealSchuman Publishers, 2003 [4].

Badke, William. Research Strategies: Finding Your Way Through the Information Fog. 2nd ed. New York: Iuniverse, 2004 [3].

Gibaldi, Joseph. MLA Handbook for Writers of Research Papers. 6th ed. New York: Modern Language Association of America, 2003 [3].

Clark, Carol Lea. A Student's Guide to the Internet. 2nd ed. Upper Saddle River, NJ: Prentice Hall, 1998 [2].

Hacker, Diana and Barbara Fister, Research and Documentation in the Electric Age. 3rd ed. Boston, MA: Bedford/St. Martins, 2002 [2].

Harnack, Andrew and Gene Kleppinger. Online: A Reference Guide to Using Internet Sources. Boston: Bedford/St. Martin's, 2001 [2].

American Psychological Association. Publication Manual of the American Psychological Association. 5th ed. Washington, DC: American Psychological Association, 2001.

Booth, Wayne C., Gregory G. Colomb and Joseph M. Williams. The Craft of Research. 2nd ed. Chicago: University of Chicago Press, 2003.

Garson, G. David. Computer Technology and Social Issues. Harrisburg, PA: Idea Group, 1997.

Gates, Jean Key. Guide to the Use of Libraries \& Information Sciences. 7th ed. New York: McGraw-Hill, 1994.

Heckman, Grant. Nelson Guide to Web Research, 2000/2001. Scarborough, ON: Nelson Thomson Learning, 2001.

Mann, Thomas, The Oxford Guide to Library Research. New York: Oxford University Press, 1998.

Riedling, Ann Marlow. Learning to Learn: A Guide to Becoming Information Literate. New York: Neal-Schuman Publishers, 2002.

Tensen, Bonnie L. Research Strategies for the Digital Age. Boston, MA: Thomson Wadsworth, 2004.

Turabian, Kate L., John Grossman and Alice Bennett. A Manual for Writers of Term Papers, Theses, and Dissertations. 6th ed. Chicago: University of Chicago Press, 1996.

Whitson, Donna L., and Donna D. Amstutz. Accessing Information in a Technological Age. Malabar, FL: Krieger Pub. Co., 1997. 